\title{
Roles of Sestrin2 and Ribosomal Protein S6 in Transient Global Ischemia-Induced Hippocampal Neuronal Injury
}

\author{
Yao-Chung Chuang ${ }^{1,2,3, \dagger}$, Jenq-Lin Yang ${ }^{2, \dagger}$, Ding-I Yang ${ }^{4}$, Tsu-Kung Lin ${ }^{1}$, Chia-Wei Liou ${ }^{1}$ and \\ Shang-Der Chen $1,2, *$
}

Received: 16 September 2015 ; Accepted: 23 October 2015 ; Published: 4 November 2015

Academic Editor: Katalin Prokai-Tatrai

1 Department of Neurology, Kaohsiung Chang Gung Memorial Hospital, College of Medicine, Chang Gung University, Kaohsiung 833, Taiwan; ycchuang@adm.cgmh.org.tw (Y.-C.C.);

tklin@adm.cgmh.org.tw (T.-K.L.); cwliou@ms22.hinet.net (C.-W.L.)

2 Center for Translational Research in Biomedical Sciences, Kaohsiung Chang Gung Memorial Hospital, Kaohsiung 833, Taiwan; jyang@adm.cgmh.org.tw

3 Department of Neurology, Faculty of Medicine, College of Medicine, Kaohsiung Medical University, Kaohsiung 833, Taiwan

4 Institute of Brain Science, National Yang-Ming University, Taipei 112, Taiwan; diyang@ym.edu.tw

* Correspondence: chensd@adm.cgmh.org.tw; Tel.: +886-7-731-7123; Fax: +886-7-731-8762

$\dagger$ These authors contributed equally to this work.

\begin{abstract}
Recent studies suggested that sestrin2 is a crucial modulator for the production of reactive oxygen species (ROS). In addition, sestrin2 may also regulate ribosomal protein S6 (RpS6), a molecule important for protein synthesis, through the effect of mammalian target of rapamycin (mTOR) complex that is pivotal for longevity. However, the roles of sestrin2 in cerebral ischemia, in which oxidative stress is one of the major pathogenic mechanisms, are still less understood. In this study, we hypothesized that sestrin 2 may protect hippocampal CA1 neurons against transient global ischemia (TGI)-induced apoptosis by regulating RpS6 phosphorylation in rats. We found that sestrin 2 expression was progressively increased in the hippocampal CA1 subfield $1-48 \mathrm{~h}$ after TGI, reaching the maximal level at $24 \mathrm{~h}$, and declined thereafter. Further, an increased extent of RpS6 phosphorylation, but not total RpS6 protein level, was observed in the hippocampal CA1 subfield after TGI. The sestrin 2 siRNA, which substantially blocked the expression of TGI-induced sestrin2, also abolished RpS6 phosphorylation. TGI with reperfusion may induce oxidative stress with the resultant formation of 8-hydroxy-deoxyguanosine (8-OHdG). We found that sestrin2 siRNA further augmented the formation of $8-\mathrm{OHdG}$ induced by TGI with reperfusion for $4 \mathrm{~h}$. Consistently, sestrin 2 siRNA also enhanced apoptosis induced by TGI with reperfusion for $48 \mathrm{~h}$ based on the analysis of DNA fragmentation by agarose gel electrophoresis, DNA fragmentation sandwich ELISA, and the terminal deoxynucleotidyl transferase-mediated dUTP-biotin nick end labeling (TUNEL) assay. Together these findings indicated that TGI-induced sestrin2 expression contributed to RpS6 phosphorylation and neuroprotection against ischemic injury in the hippocampal CA1 subfield.
\end{abstract}

Keywords: transient global ischemia; hippocampus CA1 neurons; oxidative stress; ribosomal protein S6; sestrin2

\section{Introduction}

Sestrins belong to a family of highly conserved proteins initially discovered as p53-inducible proteins and are believed to protect cells against various insults [1]. Mammalian cells express three isoforms of sestrins, namely sestrin1, sestrin2, and sestrin3 [2-4]. Several mechanisms have been 
proposed to be responsible for the protective roles of sestrins. One is that sestrins can function as an antioxidant to scavenge excessive reactive oxygen species (ROS) [3]. The other mechanism is that, under a stressful condition, p53-induced sestrins may activate AMP-dependent protein kinase (AMPK) accompanied by suppression of mammalian target of rapamycin (mTOR), leading ultimately to autophagy induction [5]. Sestrin2, also known as hypoxia-inducible gene95 (Hi95), is vital for metabolic stability under prolonged hypoxia [3]. Sestrin2 is an acute response protein and plays a crucial role under various conditions such as excessive oxidative stress, DNA damage, hypoxia, mitochondrial dysfunction, and amyloid beta-induced neurotoxicity [6-10]. However, the study of sestrin2 in cerebral ischemia is limited. In an experimental model of acute stroke, sestrin2 was highly induced in the cortical area based on the histological study, suggesting a potentially important role of sestrin2 in the ischemic brain [1]. These results may denote the pivotal role of sestrin2 in tissues under ischemic or hypoxic conditions that may be worthy of further exploration.

Ribosomal protein S6 (RpS6) is an evolutionarily conserved protein that spans 236-253 residues in various species including yeast, plants, invertebrates, and vertebrates [11]. The essential role of ribosomes is protein translation and it is, therefore, thought to be involved in regulation of protein synthesis. RpS6 is critically implicated in liver regeneration, thymus gland development, and T-cell maturation in peripheral lymphoid organs [12]. RpS6 may be subjected to phosphorylation under various physiological, pathological, and pharmacological stimuli [11]. The physiological roles of RpS6 phosphorylation include global protein synthesis, translational control of mRNAs, cell proliferation, and glucose homeostasis [11]. In a recent study [13], it was demonstrated that ischemic preconditioning results in the phosphorylation of RpS6 in mouse hearts, which exerts protective effects against oxidative stress that can be disrupted by the RpS6 siRNA.

Recently, emerging evidence suggested that, under stressful conditions, the sestrin2 signaling pathway involves p53, AMPK, and mTOR [14,15] as well as mTOR-regulated RpS6 expression [16]. It is thus reasonable to speculate that, under cerebral ischemic insult, sestrin2 and RpS6 may exert protective effects to counteract the detrimental effect of ischemia and decrease neuronal injury. However, the potential link between sestrin 2 and RpS6 in cerebral ischemia has never been reported before. In the present study, we therefore investigated the hypothesis that the sestrin2 signaling pathway plays a protective effect in the hippocampal CA1 subfield in transient global ischemia (TGI)/reperfusion through the regulation of RpS6 phosphorylation.

\section{Results and Discussion}

\subsection{Temporal Changes of Sestrin2 and RpS6 Expressions in the Hippocampal CA1 Subfield after TGI}

We first examined whether sestrin2 was induced by TGI in the hippocampal CA1 subfield. Protein immunoblot showed an evident increase of sestrin2 expression in the hippocampal CA1 subfield 1-48 $\mathrm{h}$ after TGI, reaching the maximal level at $24 \mathrm{~h}$ (Figure 1A). It was reported that the sestrin2 signaling pathway involves mTOR [14,15], and mTOR may regulate RpS6 expression [16]. Emerging evidence also revealed that RpS6 plays a key role in cardiac protection under ischemia [13]. It is therefore intriguing to know whether the expression of RpS6 is affected by TGI in the hippocampal CA1 subfield. The results shown in Figure 1B indicated that TGI with reperfusion up to $48 \mathrm{~h}$ failed to affect the expression of total RpS6; however, a progressive augmentation of RpS6 phosphorylation (p-RpS6) was detected in rat hippocampal CA1 regions in 1-48 h after TGI. Thus, TGI/reperfusion selectively induces p-RpS6, but not the total RpS6 expression, in the CA1 subfield of the hippocampus in rats.

\subsection{Sestrin2 siRNA Silences Sestrin2 Expression and Diminishes p-RpS6 Expression in the Hippocampal CA1 Subfield after TGI}

To further clarify the pivotal roles of sestrin2 in this ischemic paradigm of the brain, a molecular approach by microinjecting sestrin 2 siRNA bilaterally into the hippocampal CA1 subfields was 
adopted to elucidate the underlying mechanisms. Results showed that sestrin2 siRNA successfully down-regulated sestrin2 expression in the hippocampal CA1 subfield after TGI (Figure 2A). As sestrin2 signaling may regulate p-RpS6 expression [14-16], we therefore tested whether the suppression of sestrin 2 may affect p-RpS6 expression in ischemia/reperfusion. Results indicated that the sestrin 2 siRNA reduced the levels of p-RpS6 that were induced by 10 min of TGI with $24 \mathrm{~h}$ of reperfusion (Figure 2B), suggesting that TGI-induced sestrin2 contributed to the expression of $\mathrm{p}-\mathrm{RpS6}$.
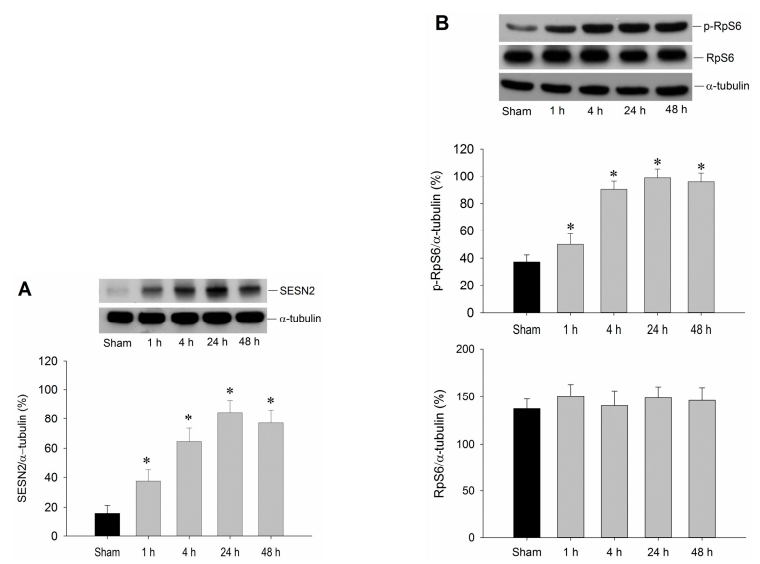

Figure 1. Transient induction of sestrin 2 and RpS6 by TGI/reperfusion. The rats were under a $10 \mathrm{~min}$ of TGI followed by reperfusion for indicated times. Sham-operated animals served as negative controls. Hippocampal CA1 samples were then collected for Western blotting to detect expression levels of sestrin2 (A) as well as RpS6 and p-RpS6 (B). The blots were also re-probed with an anti- $\alpha$-tubulin antibody as a loading control in each lane. Values are mean \pm SEM from representative blots and quantitative analyses from five to seven animals in each experimental group are shown. ${ }^{*} p<0.05$ vs. sham control group in the Scheffe multiple-range test. SENS2: sestrin2.
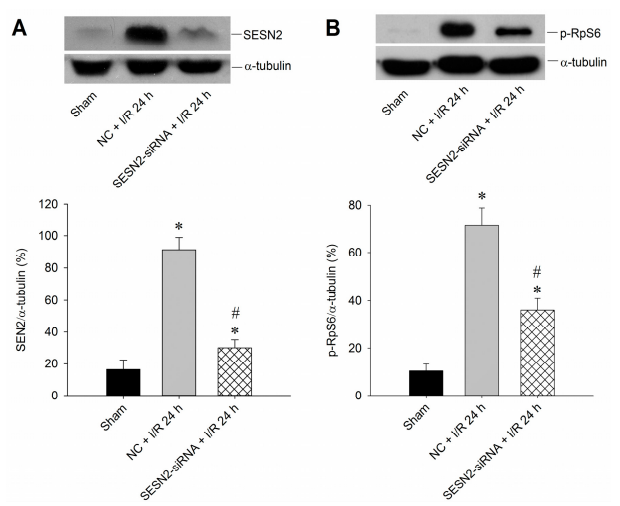

Figure 2. Sestrin 2 siRNA decreases expression of both sestrin2 and p-RpS6 in the hippocampal CA1 subfield after TGI/reperfusion. (A) Rats were microinjected into bilateral CA1 subfields with control siRNA or sestrin 2 siRNA $24 \mathrm{~h}$ before TGI. Total proteins of the hippocampal CA1 subfield were collected from the sham-operated controls without siRNA microinjection (Sham), and the rats injected with negative control siRNA (NC + I/R $24 \mathrm{~h}$ ) or the sestrin2 siRNA (SESN2 + I/R $24 \mathrm{~h}$ ), followed by $10 \mathrm{~min}$ of TGI and $24 \mathrm{~h}$ of reperfusion before detection of sestrin 2 expression; (B) The experimental condition was the same as in (A) except that the detection of p-RpS6 was conducted. In both (A) and (B), the same blots were also re-probed with an anti- $\alpha$-tubulin antibody to serve as a loading control in each lane. Values are mean \pm SEM from four to six animals per experimental group. ${ }^{*} p<0.05$ vs. sham-control group; ${ }^{\#} p<0.05$ vs. negative control siRNA + I/R in the Scheffe multiple-range test. I/R: ischemia/reperfusion. NC: negative control siRNA. SENS2: sestrin2. 


\subsection{Injection of Sestrin2-siRNA Augments Oxidative Stress and Increases Neuronal Injury in the Hippocampal CA1 Subfield after TGI}

To further clarify the pivotal role of sestrin2 in this ischemic paradigm of the brain, we investigated the effects of sestrin 2 siRNA over TGI-dependent oxidative stress and apoptosis. We found that pretreatment with sestrin 2 siRNA significantly augmented the extent of DNA oxidation, as evidenced by the increased numbers of 8-OHdG-positive cells in the hippocampal CA1 subfield $4 \mathrm{~h}$ after onset of reperfusion (Figure 3A); quantitative data confirmed this finding (Figure 3B). These findings are compatible with our previous results of quantifying the levels of 8-OHdG using a DNA oxidation kit [17]. Furthermore, the suppression of sestrin2 by siRNA further enhanced the extents of hippocampal neuronal apoptosis based on various experimental approaches. These included agarose gel electrophoresis to detect the extents of DNA fragmentation (Figure 4A), sandwich DNA fragmentation ELISA to quantitatively determine the amounts of oligonucleosomes in hippocampal tissue homogenates (Figure 4B), and TUNEL staining with quantitative data (Figure 4C,D) to detect apoptosis, all within $48 \mathrm{~h}$ after ischemia/reperfusion, as has been reported previously [17-19]. Taken together, these findings revealed that inhibition of sestrin2 expression may enhance oxidative damage and apoptosis-related DNA fragmentation in the hippocampal CA1 subfield after TGI.
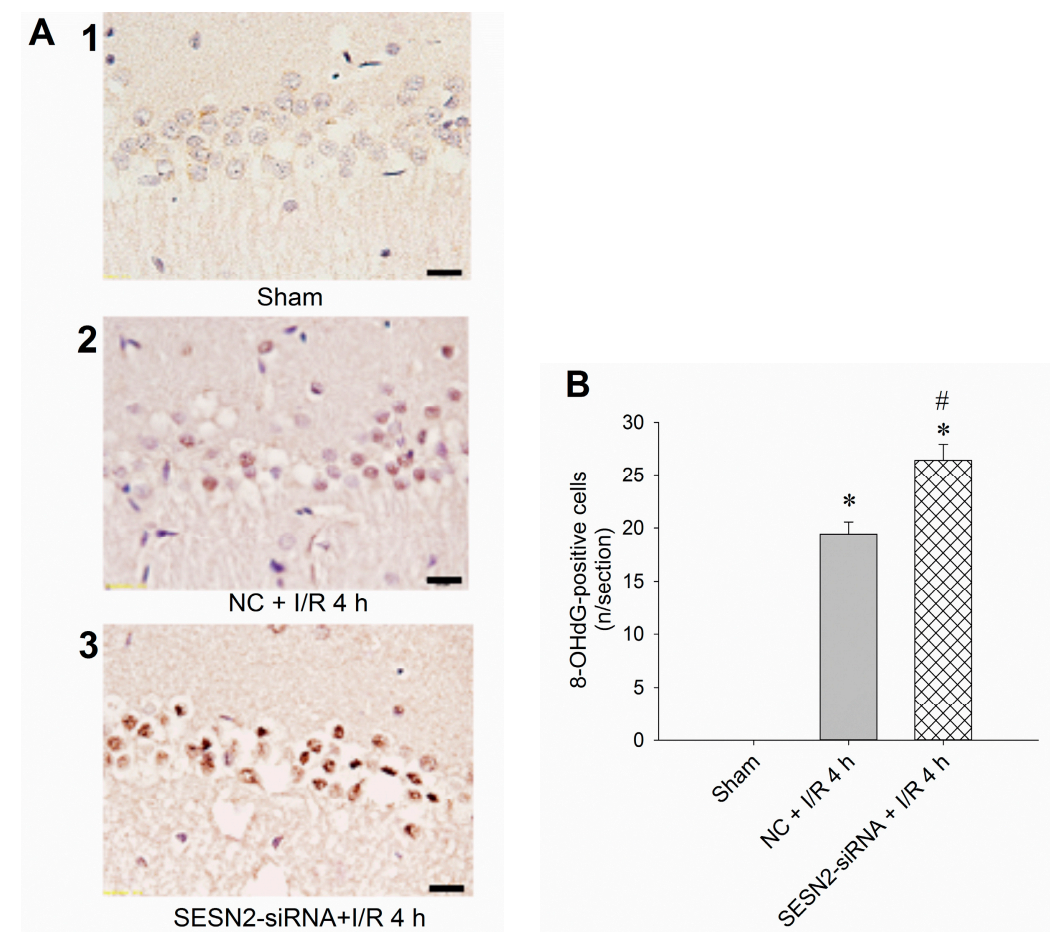

Figure 3. Sestrin 2 siRNA augments oxidative stress in the hippocampal CA1 subfield after TGI. (A) Rats were microinjected with negative control siRNA (NC + I/R $4 \mathrm{~h}$ ) or the sestrin2 siRNA (sestrin 2 siRNA + I/R $4 \mathrm{~h}$ ) into the CA1 subfield $24 \mathrm{~h}$ before $10 \mathrm{~min}$ of TGI with reperfusion for $4 \mathrm{~h}$. The sham-operated controls without siRNA microinjection served as controls (Sham). The hippocampal CA1 subfield was subjected to immunohistochemistry for quantitative assessments of 8-OHdG as an index for oxidative DNA damage; (B) Values are shown as mean \pm SEM from four to six animals in each experimental group. ${ }^{*} p<0.05$ vs. sham control group and ${ }^{\#} p<0.05$ vs. negative control siRNA + I/R in the Scheffe multiple-range test. Scale bar: $20 \mu \mathrm{m}$. I/R: ischemia/reperfusion. NC: negative control siRNA. SENS2: sestrin2.

\subsection{Discussion}

In the present study, we showed that sestrin2 expression was enhanced in the hippocampal CA1 subfield after TGI. An elevated level of p-RpS6, which is important for protein synthesis and may 
possess protective effects under the ischemic condition, was also detected in the hippocampal CA1 subfield after TGI. Down-regulation of sestrin 2 by siRNA resulted in the decreased extent of p-RpS6 in the hippocampal CA1 subfield after TGI. Attenuation of sestrin 2 expression by siRNA also increased the extents of DNA oxidation and apoptosis in hippocampal CA1 neuronal cells. Together, these results demonstrate that TGI can induce the expression of sestrin 2 in the hippocampal CA1 subfield, which may represent an endogenous protective mechanism in response to cerebral ischemia in part through regulation of $\mathrm{p}-\mathrm{RpS6}$.
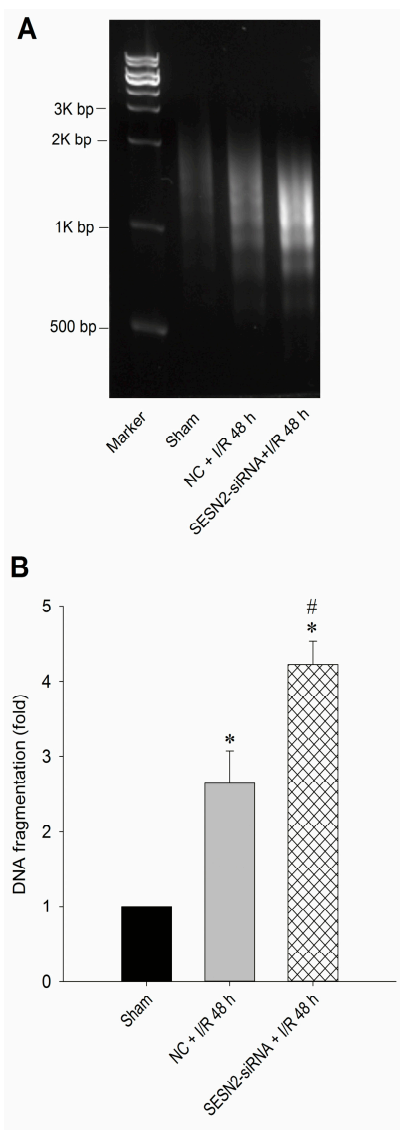
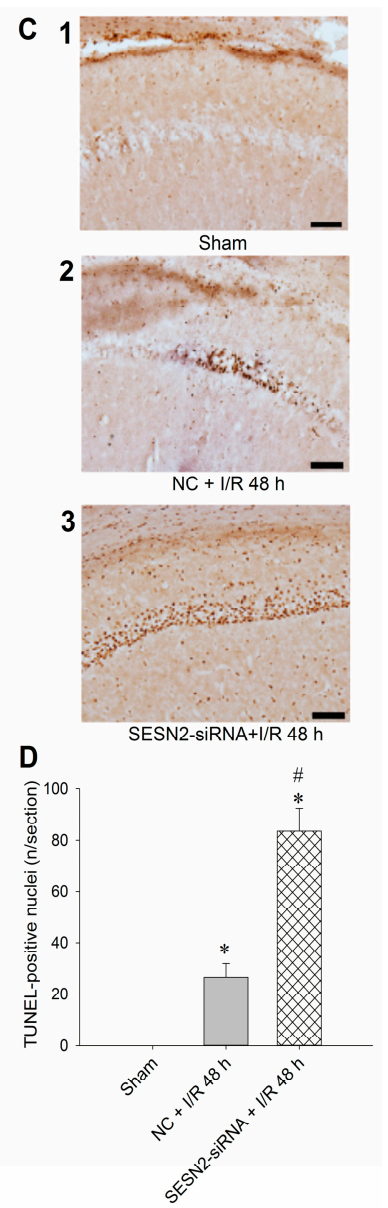

Figure 4. Sestrin2 siRNA augments apoptosis-related neuronal damage in the hippocampal CA1 subfield after TGI. The experimental protocol was the same as described in Figure 3 except that the reperfusion time was $48 \mathrm{~h}$. (A) The genomic DNA was subjected to PCR assay to reveal apoptosis-related DNA fragmentation by agarose gel electrophoresis; (B) The tissue homogenates of the hippocampal CA1 subfields were subjected to DNA fragmentation sandwich ELISA to assess histone-associated DNA fragments in the cytoplasm as a quantitative measure for the DNA fragmentation; (C,D) Hippocampal slices were subjected to TUNEL staining to resolve the extents of apoptosis. Values in (B,D) are mean \pm SEM from five to seven animals in each experimental group. ${ }^{*} p<0.05$ vs. sham control group and ${ }^{\#} p<0.05$ vs. negative control siRNA + I/R in the Scheffe multiple-range test. Scale bar in (C): $100 \mu \mathrm{m}$. I/R: ischemia/reperfusion. NC: negative control siRNA. SENS2: sestrin2.

In the current study, the physiological parameters (i.e., $\mathrm{pH}, \mathrm{pCO}_{2}, \mathrm{pO}_{2}$, mean arterial blood pressure, etc.) before and after the induction of TGI were not provided. Nevertheless, our protocols for TGI were based on the previously reported model [20]. In that TGI procedure, all the physiological parameters, including $\mathrm{pH}, \mathrm{pCO}_{2}, \mathrm{pO}_{2}$, and mean arterial blood pressure, were not different before and after the TGI procedures among different sets of mean arterial blood pressure from $36-40 \mathrm{mmHg}$ 
(mild hypotension group), 31-35 $\mathrm{mmHg}$ (moderate hypotension group), to $26-30 \mathrm{mmHg}$ (severe hypotension group) [20]. Given our previous publications [17-19,21], together with the oxidative damages of the hippocampal CA1 subfield shown in the present study, this is a feasible model for exploring the molecular mechanisms underlying TGI-induced hippocampal neuronal injuries.

Selective neuronal loss in the hippocampal CA1 subfield is a histological feature of TGI and reperfusion which occurs days after the initial ischemic insult [22]. Despite many theories and efforts to explain this postponed neuronal death in the CA1 subfield of the hippocampus, the underlying mechanisms remain unclear. Common pathogenic mechanisms, including impaired mitochondrial function, increased oxidative damage, excitotoxicity, and inflammation, are all implicated in various ischemic conditions [23,24]. It was suggested that ischemic neuronal damage is mainly due to an inflammatory pathogenesis. The inflammatory process is engaged in all phases of the ischemic cascades, from the early detrimental events triggered by arterial occlusion to the late restorative processes underlying post-ischemic tissue repair, and both the innate and adaptive immune response may offer an innovative therapeutic strategy $[25,26]$. Activation of inflammation-related signaling pathways in ischemic stroke includes the Toll-like receptors pathway, the mitogen-activated protein kinases pathway, and the nuclear factor-kappa B pathway [27]. In addition to inflammatory responses that play the main role in ischemic pathogenesis, the crucial participant of oxidative stress is well known in cerebral ischemia $[23,24,28]$. Drugs and chemical compounds possessing the characters of anti-oxidative stress can exert beneficial effects under ischemic insults $[29,30]$. Notably, inflammation and oxidative stress are mutually implicated with each other. For example, superoxide anion produced by the NADPH oxidase in activated microglia may interact with nitric oxide (NO) that is generated from inflammatory responses to form the active oxidant peroxynitrite [31]. In the current study, we revealed the crucial roles of sestrin 2 in attenuating oxidative damage caused by TGI/reperfusion. However, whether the observed sestrin2 effect may also link to the attenuation of inflammatory responses requires further investigation.

Sestrins are stress-inducible proteins capable of protecting cells against various insults [1]. Among them, sestrin 2 appears to be a stress sensor that is protective against stress-induced apoptosis and incorporates the pro-survival function of Akt and the negative regulation of mTOR [14,32]. It has been shown that sestrin2 ablation aggravates obesity-induced mTORC1-S6K pathways, glucose intolerance, insulin resistance, and hepatosteatosis [33]. These results reveal an important homeostatic function of sestrin2 in the control of lipid and glucose metabolism [33]. Emerging evidence also suggests that, under stressful conditions, sestrin 2 expression involves the AMPK and mTOR-S6K pathways [15]. While the exact function of sestrin2 is yet to be clarified, and sestrin2 may control intricate cellular functions in response to different stress conditions [1], evidence from various ischemic conditions suggests that sestrin 2 may possess a protective role under cerebral ischemia [34,35]. It was reported that renal ischemia-reperfusion injury up-regulated the expression of sestrin2 in the proximal tubules to protect the renal tubules from acute kidney injury [34]. In a recent study, sestrin2 exerted a cardioprotective effect against ischemia/reperfusion injury, serving as an LKB1-AMPK scaffold to commence AMPK activation during ischemic insults [35]. Consistent with these findings, in this study we showed that TGI increases sestrin2 expression in the hippocampal CA1 subfield with a progressive augmentation from 1-48 h that peaked at $24 \mathrm{~h}$ after reperfusion (Figure 1A). This finding may denote a potential role of sestrin 2 in this ischemic condition. Although mTOR may regulate protein translation, which is important for cellular growth and proliferation, reports about mTOR are conflicting, with either protective or detrimental effect in ischemia/reperfusion [36-38]. In a recent ischemic preconditioning study of the heart that involved mTOR expression, p-RpS6 represented a convergent point for cardioprotection [13]. As the sestrin2 signaling pathway involving mTOR [14,15] and mTOR may regulate RpS6 expression [16], it is tempting to speculate the inter-relationship between sestrin2 and RpS6 under TGI. In this study, we showed a significant change of $\mathrm{p}-\mathrm{RpS6}$, but not the total RpS6, in the hippocampal CA1 subfield after TGI, which suggests an important role of p-RpS6 in this ischemia paradigm (Figure 1B). These results 
are in line with the contention that sestrin 2 expression and p-RpS6 may have a potentially protective effect in the hippocampal CA1 subfield in TGI/reperfusion.

To show the pivotal role of sestrin2 in this ischemic paradigm, we used sestrin 2 siRNA to silence its expression in the hippocampal CA1 subfield after TGI (Figure 2A). Concomitantly, the extent of p-RpS6 decreased with sestrin2 siRNA treatment (Figure 2B). RpS6, known to be vital for the regulation of protein synthesis [11], may be important to counteract oxidative stress under an ischemic condition with phosphorylated states. It was known that an excessive oxidative stress underlies neuronal cell damages in the CA1 subfield of the hippocampus after TGI [17,19,21]. The extent of TGI-induced oxidative neuronal damage is linked to the expression of sestrin2, which is based on the findings that oxidative stress-induced DNA damage was augmented after sestrin 2 siRNA treatment in the hippocampal CA1 subfield after TGI (Figure 3). Accordingly, the down-regulation of sestrin2 expression augments neuronal injury in the hippocampal CA1 subfield after TGI (Figure 4). Although we did not show direct evidence between RpS6 and oxidative stress in this study, it was known that the down-regulation of p-RpS6 by RpS6 siRNA abrogate the protective ability against oxidative stress in ischemic heart conditions [13]. Thus, at least partly, sestrin 2 may exert an antioxidant effect through p-RpS6 under the cerebral ischemic condition.

\section{Experimental Section}

\subsection{Animals and Transient Global Ischemia}

The experimental procedures conformed to the guidelines of our institutional committee on experimental animals in this study. Male adult Sprague-Dawley rats (250-325 g) were purchased from BioLASCO Taiwan Co., Ltd. (Taipei, Taiwan). They were housed in an Association for Assessment and Accreditation of Laboratory Animal Care (AAALAC) International-accredited animal facility under temperature control $\left(24-25^{\circ} \mathrm{C}\right)$ and $12 \mathrm{~h}$ light-dark cycle. Standard laboratory rat chow and tap water were available ad libitum. Rats were first anesthetized with chloral hydrate $(400 \mathrm{mg} / \mathrm{kg}$, i.p.) to perform preparative surgery. The TGI model was performed as previously reported [20,21].

\section{2. siRNA Administration}

Microinjection of siRNA into the hippocampal CA1 subfield was performed bilaterally using a stereotaxically positioned 27-gauge stainless steel needle connected to a $0.5 \mu \mathrm{L}$ Hamilton microsyringe (Hamilton Company, Reno, NV, USA) as previously reported [17,19,21]. To inhibit sestrin2 expression, we used pre-designed sestrin2 siRNA from MISSION ${ }^{\circledR}$ siRNA (Sigma-Aldrich Ltd., St. Louis, MO, USA); the sequences were as follows: sense, 5'-CAGAGUAUUGUAACAU-3', antisense, 5'-AUAGUGUUACAAUACUCUG-3'. For negative control siRNA(NC), the sequences were as follows: $5^{\prime}$-GAUCAUACGUGCGAUCAGA- $3^{\prime}$, antisense, $5^{\prime}$-UCUGAUCGCACGUAUGAUC-3'. The final concentration of siRNA was $0.05 \mathrm{nM}$ in a total volume of $400 \mathrm{~nL}$ for injection into each side of the hippocampal CA1 subfield $24 \mathrm{~h}$ before TGI.

\subsection{Tissue Sample Collection from the Hippocampus}

At pre-designed time intervals $(1,4,24$, or $48 \mathrm{~h})$ after TGI, rats were again anesthetized and perfused transcardially with $50 \mathrm{~mL}$ of warm $\left(37.8{ }^{\circ} \mathrm{C}\right)$ saline containing heparin $(100 \mathrm{U} / \mathrm{mL})$ as previously reported [39-41]. The brain was taken out quickly under visual check and then placed on a piece of gauze moistened with ice-cold $0.9 \%$ saline. Tissues from the bilateral hippocampal CA1 area were collected and these samples were stored at $-80{ }^{\circ} \mathrm{C}$ until use $[17,19,21]$. The protein concentration from the hippocampal CA1 tissue samples were measured with the BCA Protein Assay (Pierce, Rockford, IL, USA). 


\subsection{Western Blotting}

Samples $(20-40 \mu \mathrm{g}$ of protein) were resolved through $2 \%$ SDS/polyacrylamide gels and transferred to PDVF membranes as previously reported $[17,19,21]$. The membranes were incubated with a primary anti-sestrin2 antibody (Abcam, Cambridge, MA, USA), phospho-RpS6 (Ser235/236), RpS6 antibody (Cell Signaling, Danvers, MA, USA), or mouse monoclonal antiserum against á-tubulin (Santa Cruz Biotechnology, Santa Cruz, CA, USA) for 1-2 h at room temperature. The specific antibody-antigen complex was detected and measured semiquantitatively as previously reported $[17,19,21]$. The color reaction was developed by the Blot AP System from Promega (Fitchburg, WI, USA).

\subsection{Immunohistochemical Staining}

After TGI and reperfusion, rats were anesthetized with pentobarbital $(100 \mathrm{mg} / \mathrm{kg}$, i.p. $)$ and perfused transcardially with $150 \mathrm{~mL}$ of physiological saline; then followed by perfusion $400 \mathrm{~mL}$ of $4 \%$ paraformaldehyde in $0.1 \mathrm{M}$ PBS for tissue fixation. The forebrains containing the dorsal hippocampus were dissected carefully. The brain sections were then blocked and fixed with additional $2 \mathrm{~h}$ in the same perfusion fixatives and thereafter transferred to a solution containing $30 \%$ sucrose in $0.1 \mathrm{M}$ PBS for immunohistochemical staining. The brain sections embedded in tissue freezing medium (Sakura Finetek, Torrance, CA, USA) were serially sectioned throughout the rostral-caudal extent of the hippocampus at $10 \mu \mathrm{m}$ thickness on a cryostat, and mounted on Superfrost/plus slides. The sections were permeabilized with $0.3 \%$ Triton X-100/10\% horse serum in 0.01 M PBS for $20 \mathrm{~min}$ then incubated with primary antibodies. A primary anti-8OH-dG antibody (Cell Signaling, Danvers, MA, USA) was then applied to the sections overnight at $4{ }^{\circ} \mathrm{C}$. The next day, the brain sections were incubated with a secondary biotinylated antibody (Vector Laboratories, Burlingame, CA, USA) for $1 \mathrm{~h}$. The sections were washed and then incubated with $A B C$ Elite complex (Vector Laboratories) for $1 \mathrm{~h}$. The immunostainings of anti-8OH-dG antibody were visualized with DAB (Sigma Co., St. Louis, MO, USA). Images were captured under an Olympus AX70 (Olympus, Tokyo, Japan) light microscope. The numbers of 8-OHdG-positive cells were counted in the length of $250 \mu \mathrm{m}$ of the pyramidal cell layer, in the middle of the hippocampal CA1 subfield, which were denoted as 8-OHdG-positive cells/section.

\subsection{Qualitative and Quantitative Analysis of DNA Fragmentation}

To qualitatively evaluate DNA fragmentation, total DNA were extracted from the hippocampal tissues and nucleosomal DNA ladders were amplified by a PCR kit (Maxim Biotech, San Francisco, CA, USA); then the samples were separated by $1 \%$ agarose gel electrophoresis. To quantitatively evaluate DNA fragmentation, a cell death enzyme-linked immunosorbent assay (Roche Molecular Biochemicals, Mannheim, Germany) was used to assess the histone-associated DNA fragments in the cytoplasm as previously reported $[17,19]$.

\subsection{Terminal Deoxynucleotidyl Transferase-Mediated dUTP-Biotin Nick End Labeling (TUNEL) Staining}

The rats were processed for TUNEL staining $48 \mathrm{~h}$ after the onset of reperfusion following a 10 min episode of TGI with a commercial in situ apoptosis detection kit (ApopTag, Intergen Company, Purchase, NY, USA) as previously reported [17]. The TUNEL-positive cells were counted with the length of $1 \mathrm{~mm}$ of the pyramidal cell layer, in the middle of the hippocampal CA1 subfield, using an Olympus AX70 microscope, and were stated as the TUNEL-positive cells/section.

\subsection{Statistical Analysis}

Results are expressed as mean \pm SEM. One way analysis of variance followed by the Scheffe multiple range tests for post-hoc assessment of individual means were used to compare the group mean differences. A $p$-value less than 0.05 was considered significant. 


\section{Conclusions}

In conclusion, this study showed that sestrin2 may function as an endogenous protective mechanism in cerebral ischemia by affecting p-RpS6 expression, modulating oxidative status, and influencing neuronal damage. Any measurement to enhance sestrin2 expression in cerebral ischemia should have clinical potential in counteracting ROS-related neuronal damage.

Acknowledgments: This work was supported by research grants NSC 100-2314-B-182-062 and MOST103-2314-B-182-026-MY2 from the Ministry of Science and Technology, Taiwan and BMRP555 from Chang Gung Memorial Hospital to Shang-Der Chen.

Author Contributions: Yao-Chung Chuang, Jenq-Lin Yang and Shang-Der Chen researched data, contributed to the discussion, and wrote the manuscript. Shang-Der Chen designed the study. Jenq-Lin Yang did the animal study. Ding-I Yang, Tsu-Kung Lin, Chia-Wei Liou contributed to the discussion, reviewed and edited the manuscript.

Conflicts of Interest: The authors declare no conflict of interest.

\section{References}

1. Budanov, A.V.; Shoshani, T.; Faerman, A.; Zelin, E.; Kamer, I.; Kalinski, H.; Gorodin, S.; Fishman, A.; Chajut, A.; Einat, P.; et al. Identification of a novel stress-responsive gene Hi95 involved in regulation of cell viability. Oncogene 2002, 21, 6017-6031. [CrossRef] [PubMed]

2. Peeters, H.; Debeer, P.; Bairoch, A.; Wilquet, V.; Huysmans, C.; Parthoens, E.; Fryns, J.P.; Gewillig, M.; Nakamura, Y.; Niikawa, N.; et al. PA26 is a candidate gene for heterotaxia in humans: Identification of a novel PA26-related gene family in human and mouse. Hum. Genet. 2003, 112, 573-580. [PubMed]

3. Budanov, A.V.; Sablina, A.A.; Feinstein, E.; Koonin, E.V.; Chumakov, P.M. Regeneration of peroxiredoxins by p53-regulated sestrins, homologs of bacterial AhpD. Science 2004, 304, 596-600. [CrossRef]

4. Velasco-Miguel, S.; Buckbinder, L.; Jean, P.; Gelbert, L.; Talbott, R.; Laidlaw, J.; Seizinger, B.; Kley, N. PA26, a novel target of the p53 tumor suppressor and member of the GADD family of DNA damage and growth arrest inducible genes. Oncogene 1999, 18, 127-137. [CrossRef] [PubMed]

5. Budanov, A.V. Stress-responsive sestrins link p53 with redox regulation and mammalian target of rapamycin signaling. Antioxid. Redox Signal. 2011, 15, 1679-1690. [CrossRef] [PubMed]

6. Essler, S.; Dehne, N.; Brune, B. Role of sestrin2 in peroxide signaling in macrophages. FEBS Lett. 2009, 583, 3531-3535. [CrossRef] [PubMed]

7. Sanli, T.; Linher-Melville, K.; Tsakiridis, T.; Singh, G. Sestrin2 modulates AMPK subunit expression and its response to ionizing radiation in breast cancer cells. PLoS ONE 2012, 7, e32035. [CrossRef] [PubMed]

8. Shin, B.Y.; Jin, S.H.; Cho, I.J.; Ki, S.H. Nrf2-ARE pathway regulates induction of Sestrin-2 expression. Free Radic. Biol. Med. 2012, 53, 834-841. [CrossRef] [PubMed]

9. Chen, Y.S.; Chen, S.D.; Wu, C.L.; Huang, S.S.; Yang, D.I. Induction of sestrin2 as an endogenous protective mechanism against amyloid beta-peptide neurotoxicity in primary cortical culture. Exp. Neurol. 2014, 253, 63-71. [CrossRef]

10. Wu, C.L.; Chen, S.D.; Yin, J.H.; Hwang, C.S.; Yang, D.I. Nuclear Factor-kappaB-dependent sestrin2 induction mediates the antioxidant effects of BDNF against mitochondrial inhibition in rat cortical neurons. Mol. Neurobiol. 2015, 26. [CrossRef]

11. Meyuhas, O. Physiological roles of ribosomal protein S6: One of its kind. Int. Rev. Cell Mol. Biol. 2008, 268, $1-37$.

12. Sulic, S.; Panic, L.; Barkic, M.; Mercep, M.; Uzelac, M.; Volarevic, S. Inactivation of S6 ribosomal protein gene in T lymphocytes activates a p53-dependent checkpoint response. Genes Dev. 2005, 19, 3070-3082. [CrossRef] [PubMed]

13. Yano, T.; Ferlito, M.; Aponte, A.; Kuno, A.; Miura, T.; Murphy, E.; Steenbergen, C. Pivotal role of mTORC2 and involvement of ribosomal protein S6 in cardioprotective signaling. Circ. Res. 2014, 114, 1268-1280. [CrossRef] [PubMed]

14. Budanov, A.V.; Karin, M. p53 target genes sestrin1 and sestrin2 connect genotoxic stress and mTOR signaling. Cell 2008, 134, 451-460. [CrossRef] [PubMed] 
15. Solhaug, A.; Torgersen, M.L.; Holme, J.A.; Lagadic-Gossmann, D.; Eriksen, G.S. Autophagy and senescence, stress responses induced by the DNA-damaging mycotoxin alternariol. Toxicology 2014, 326, 119-129. [CrossRef] [PubMed]

16. Magnuson, B.; Ekim, B.; Fingar, D.C. Regulation and function of ribosomal protein S6 kinase (S6K) within mTOR signalling networks. Biochem. J. 2012, 441, 1-21. [CrossRef] [PubMed]

17. Chen, S.D.; Lin, T.K.; Yang, D.I.; Lee, S.Y.; Shaw, F.Z.; Liou, C.W.; Chuang, Y.C. Roles of PTEN-induced putative kinase 1 and dynamin-related protein 1 in transient global ischemia-induced hippocampal neuronal injury. Biochem. Biophys. Res. Commun. 2015, 460, 397-403. [CrossRef] [PubMed]

18. Chen, S.D.; Lin, T.K.; Lin, J.W.; Yang, D.I.; Lee, S.Y.; Shaw, F.Z.; Liou, C.W.; Chuang, Y.C. Activation of calcium/calmodulin-dependent protein kinase IV and peroxisome proliferator-activated receptor gamma coactivator-1alpha signaling pathway protects against neuronal injury and promotes mitochondrial biogenesis in the hippocampal CA1 subfield after transient global ischemia. J. Neurosci. Res. 2010, 88, 3144-3154. [PubMed]

19. Chen, S.D.; Lin, T.K.; Yang, D.I.; Lee, S.Y.; Shaw, F.Z.; Liou, C.W.; Chuang, Y.C. Protective effects of peroxisome proliferator-activated receptors gamma coactivator-1alpha against neuronal cell death in the hippocampal CA1 subfield after transient global ischemia. J. Neurosci. Res. 2010, 88, 605-613. [PubMed]

20. Sugawara, T.; Kawase, M.; Lewen, A.; Noshita, N.; Gasche, Y.; Fujimura, M.; Chan, P.H. Effect of hypotension severity on hippocampal CA1 neurons in a rat global ischemia model. Brain Res. 2000, 877, 281-287. [CrossRef]

21. Chen, S.D.; Wu, H.Y.; Yang, D.I.; Lee, S.Y.; Shaw, F.Z.; Lin, T.K.; Liou, C.W.; Chuang, Y.C. Effects of rosiglitazone on global ischemia-induced hippocampal injury and expression of mitochondrial uncoupling protein 2. Biochem. Biophys. Res. Commun. 2006, 351, 198-203. [CrossRef] [PubMed]

22. Pulsinelli, W.A.; Brierley, J.B.; Plum, F. Temporal profile of neuronal damage in a model of transient forebrain ischemia. Ann. Neurol. 1982, 11, 491-498. [CrossRef] [PubMed]

23. Chen, S.D.; Lee, J.M.; Yang, D.I.; Nassief, A.; Hsu, C.Y. Combination therapy for ischemic stroke: Potential of neuroprotectants plus thrombolytics. Am. J. Cardiovasc. Drugs 2002, 2, 303-313. [CrossRef]

24. Chen, S.D.; Yang, D.I.; Lin, T.K.; Shaw, F.Z.; Liou, C.W.; Chuang, Y.C. Roles of oxidative stress, apoptosis, PGC-1alpha and mitochondrial biogenesis in cerebral ischemia. Int. J. Mol. Sci. 2011, 12, 7199-7215. [CrossRef]

25. Lakhan, S.E.; Kirchgessner, A.; Hofer, M. Inflammatory mechanisms in ischemic stroke: Therapeutic approaches. J. Transl. Med. 2009, 7, 97-107. [CrossRef]

26. Iadecola, C.; Anrather, J. The immunology of stroke: From mechanisms to translation. Nat. Med. 2011, 17, 796-808. [CrossRef] [PubMed]

27. Jin, R.; Liu, L.; Zhang, S.; Nanda, A.; Li, G. Role of inflammation and its mediators in acute ischemic stroke. J. Cardiovasc. Transl. Res. 2013, 6, 834-851. [CrossRef]

28. Niizuma, K.; Yoshioka, H.; Chen, H.; Kim, G.S.; Jung, J.E.; Katsu, M.; Okami, N.; Chan, P.H. Mitochondrial and apoptotic neuronal death signaling pathways in cerebral ischemia. Biochim. Biophys. Acta 2010, 1802, 92-99. [CrossRef] [PubMed]

29. Minnerup, J.; Sutherland, B.A.; Buchan, A.M.; Kleinschnitz, C. Neuroprotection for stroke: Current status and future perspectives. Int. J. Mol. Sci. 2012, 13, 11753-11772. [CrossRef] [PubMed]

30. George, P.M.; Steinberg, G.K. Novel stroke therapeutics: Unraveling stroke pathophysiology and its impact on clinical treatments. Neuron 2015, 87, 297-309. [CrossRef] [PubMed]

31. Brown, G.C.; Neher, J.J. Inflammatory neurodegeneration and mechanisms of microglial killing of neurons. Mol. Neurobiol. 2010, 41, 242-247. [CrossRef] [PubMed]

32. Ben-Sahra, I.; Dirat, B.; Laurent, K.; Puissant, A.; Auberger, P.; Budanov, A.; Tanti, J.F.; Bost, F. Sestrin2 integrates Akt and mTOR signaling to protect cells against energetic stress-induced death. Cell Death Differ. 2013, 20, 611-619. [CrossRef] [PubMed]

33. Lee, J.H.; Budanov, A.V.; Talukdar, S.; Park, E.J.; Park, H.L.; Park, H.W.; Bandyopadhyay, G.; Li, N.; Aghajan, M.; Jang, I.; et al. Maintenance of metabolic homeostasis by Sestrin2 and Sestrin3. Cell Metab. 2012, 16, 311-321. [CrossRef] [PubMed]

34. Ishihara, M.; Urushido, M.; Hamada, K.; Matsumoto, T.; Shimamura, Y.; Ogata, K.; Inoue, K.; Taniguchi, Y.; Horino, T.; Fujieda, M.; et al. Sestrin-2 and BNIP3 regulate autophagy and mitophagy in renal tubular cells in acute kidney injury. Am. J. Physiol. Ren. Physiol. 2013, 305, 495-509. [CrossRef] [PubMed] 
35. Morrison, A.; Chen, L.; Wang, J.; Zhang, M.; Yang, H.; Ma, Y.; Budanov, A.; Lee, J.H.; Karin, M.; Li, J. Sestrin2 promotes LKB1-mediated AMPK activation in the ischemic heart. FASEB J. 2015, 29, 408-417. [CrossRef] [PubMed]

36. Jonassen, A.K.; Sack, M.N.; Mjos, O.D.; Yellon, D.M. Myocardial protection by insulin at reperfusion requires early administration and is mediated via Akt and p70s6 kinase cell-survival signaling. Circ. Res. 2001, 89, 1191-1198. [CrossRef] [PubMed]

37. Khan, S.; Salloum, F.; Das, A.; Xi, L.; Vetrovec, G.W.; Kukreja, R.C. Rapamycin confers preconditioning-like protection against ischemia-reperfusion injury in isolated mouse heart and cardiomyocytes. J. Mol. Cell. Cardiol. 2006, 41, 256-264. [CrossRef] [PubMed]

38. Sciarretta, S.; Volpe, M.; Sadoshima, J. Mammalian target of rapamycin signaling in cardiac physiology and disease. Circ. Res. 2014, 114, 549-564. [CrossRef]

39. Chuang, Y.C.; Lin, T.K.; Huang, H.Y.; Chang, W.N.; Liou, C.W.; Chen, S.D.; Chang, A.Y.; Chan, S.H. Peroxisome proliferator-activated receptors gamma/mitochondrial uncoupling protein 2 signaling protects against seizure-induced neuronal cell death in the hippocampus following experimental status epilepticus. J. Neuroinflamm. 2012, 9, 1-18. [CrossRef] [PubMed]

40. Wu, K.L.; Wu, C.A.; Wu, C.W.; Chan, S.H.; Chang, A.Y.; Chan, J.Y. Redox-sensitive oxidation and phosphorylation of PTEN contribute to enhanced activation of PI3K/Akt signaling in rostral ventrolateral medulla and neurogenic hypertension in spontaneously hypertensive rats. Antioxid. Redox Signal. 2013, 18, 36-50. [CrossRef]

41. Chang, C.C.; Chen, S.D.; Lin, T.K.; Chang, W.N.; Liou, C.W.; Chang, A.Y.; Chan, S.H.; Chuang, Y.C. Heat shock protein 70 protects against seizure-induced neuronal cell death in the hippocampus following experimental status epilepticus via inhibition of nuclear factor-kappaB activation-induced nitric oxide synthase II expression. Neurobiol. Dis. 2014, 62, 241-249. [CrossRef]

(C) 2015 by the authors; licensee MDPI, Basel, Switzerland. This article is an open access article distributed under the terms and conditions of the Creative Commons by Attribution (CC-BY) license (http:/ / creativecommons.org/licenses/by/4.0/). 